\title{
RAMAN SPECTROSCOPIC EVIDENCE FOR COLINEAR ARRANGEMENT IN THE SOLID STATE OF THERMOCHROMIC DISTIBANES
}

\author{
H. BÜRGER and R. EUJEN
}

\begin{abstract}
Anorganische Chemie, FB 9, Universität-Gesamthochschule, D-5600 Wuppertal 1 (West Germany)

G. BECKER, O. MUNDT, M. WESTERHAUSEN and C. WITTHAUER

Fachbereich Chemie, Philipps-Universität, Sonderforschungbereich 127, D-3550 Marburg (West Germany)
\end{abstract}

(Received 9 August 1982)

\section{ABSTRACT}

The IR and Raman spectra of the compounds $\left(\mathrm{CH}_{3}\right)_{2} \mathrm{Sb}-\mathrm{Sb}\left(\mathrm{CH}_{3}\right)_{2}(\mathrm{I}),\left[\left(\mathrm{CH}_{3}\right)_{3} \mathrm{Si}\right]_{2} \mathrm{Sb}-$ $\mathrm{Sb}\left[\mathrm{Si}\left(\mathrm{CH}_{3}\right)_{3}\right]_{2}(\mathrm{II}),\left[\left(\mathrm{CH}_{3}\right)_{3} \mathrm{Si}\right]_{2} \mathrm{As}-\mathrm{As}\left[\mathrm{Si}\left(\mathrm{CH}_{3}\right)_{3}\right]_{2}(\mathrm{III})$ and $\left(\mathrm{C}_{6} \mathrm{H}_{5}\right)_{2} \mathrm{Sb}-\mathrm{Sb}\left(\mathrm{C}_{6} \mathrm{H}_{5}\right)_{2}$ (IV) have been studied in the liquid and solid states. Given assignments for I to III are based on normal coordinate analyses, and force constants are reported. The solid state Raman spectra of I and II exhibit strong lines near $50 \mathrm{~cm}^{-1}$, which are assigned to the longitudinal acoustic mode of an infinite linear chain of $\mathrm{Sb}$ atoms. In termolecular $\mathrm{Sb} \cdots \mathrm{Sb}$ force constants, 0.125 and $0.18 \mathrm{~N} \mathrm{~cm}^{-1}$, are determined for I and II respectively.

\section{INTRODUCTION}

It has long been known that tetramethyl distibane $\left(\mathrm{CH}_{3}\right)_{2} \mathrm{Sb}-\mathrm{Sb}\left(\mathrm{CH}_{3}\right)_{2}$ (I) changes its colour from red to pale yellow on melting [1]. In contrast, no such behaviour has been noted for other tetraalkyl and tetraaryl distibanes $\mathrm{R}_{2} \mathrm{Sb}-\mathrm{SbR}_{2}$. More recently similar colour changes have been reported for tetrakis(trimethylsilyl) $\left(\mathrm{R}=\left(\mathrm{CH}_{3}\right)_{3} \mathrm{Si}\right.$ (II)) [2] and tetrakis(trimethylgermyl) distibane $\left(\mathrm{R}=\left(\mathrm{CH}_{3}\right)_{3} \mathrm{Ge}\right)$ [3], while the corresponding diarsane, $\mathrm{R}_{2} \mathrm{As}-\mathrm{AsR}_{2}$ $\left(\mathrm{R}=\left(\mathrm{CH}_{3}\right)_{3} \mathrm{Si}\right.$ (III) ) retains its pale yellow colour on melting [4]. For $2,2^{\prime}, 5,5^{\prime}$ tetramethyl distibolyl which, in the solid state, appears iridescent purple-blue in reflected light but red to transmitted light and which melts at $99^{\circ} \mathrm{C}$ to form a pale yellow oil, a colinear packing of all of the antimony atoms along the $b$ crystal axis has been found, and the remarkable appearance of the crystal has been attributed to the short intermolecular $\mathrm{Sb} \cdots \mathrm{Sb}$ contacts, $362.5(2) \mathrm{pm}$ [5]. This contact lies exactly between the van der Waals diameter, $440 \mathrm{pm}$, and the intramolecular SbSb distance, 283.5(1) pm. The analogy to the structure of iodine in the solid state has been stressed, and compound I was presumed to adopt similarly a colinear chain structure in the solid state. 
A connection between thermochromic effect and colinear packing of the $\mathrm{Sb}$ atoms has been confirmed by comparing the crystal structures of $\mathrm{R}_{2} \mathrm{Sb}$ $\mathrm{SbR}_{2},\left(\mathrm{R}=\mathrm{C}_{6} \mathrm{H}_{5}(\mathrm{IV})\right)[6,7]$ and II [7] or III [8]. While the molecular and crystal structure of I, to our knowledge, is still unknown, trans-configurated molecules of II are packed to form infinite linear chains of Sb atoms with intra- and intermolecular SbSb distances of 286.7 and $399 \mathrm{pm}$, respectively [7]. Molecules of IV are trans-configurated as well, though in the crystal no colinear $\mathrm{SbSb} \cdots \mathrm{SbSb}$ chains are formed, and the closest $\mathrm{Sb} \cdots \mathrm{Sb}$ contacts, $429 \mathrm{pm}$, are only slightly shorter than the van der Waals radii sum [7]. In III, the molecules adopt a gauche conformation, and no intermolecular As $\cdots$ As contacts shorter than 662 pm occur [8] .

Vibrational spectroscopy, in particular laser Raman spectroscopy, should be a powerful tool to evaluate such short intermolecular contacts in colinear chains. Since the intramolecular vibrations, in particular those of higher energy $\left(>300 \mathrm{~cm}^{-1}\right)$, are not supposed to be substantially affected by the intermolecular modes, comparison of spectra obtained on the solid phase and on the melt or a solution should be a diagnostic means to detect external modes.

Recently, the IR and Raman spectra of I, of $\left(\mathrm{C}_{2} \mathrm{H}_{5}\right)_{2} \mathrm{Sb}-\mathrm{Sb}\left(\mathrm{C}_{2} \mathrm{H}_{5}\right)_{2}$ and of IV have been reported, but regrettably the low-frequency $\left(>100 \mathrm{~cm}^{-1}\right)$ region, in which the external modes are expected to occur, was not investigated by the Raman effect [9]. Based on their assignments and on temperaturedependent changes of relative intensities, the authors postulated the presence of both trans and gauche conformers of $I$ in the liquid and solid state.

In the following we report, with particular emphasis on the low-frequency region (10-400 $\left.\mathrm{cm}^{-1}\right)$, the IR and Raman spectra of the two thermochromic distibanes I and II in the solid and the liquid states and compare these with spectra of III and IV which exhibit normal behaviour on melting. Since the low-lying vibrations involve intramolecular ( $\mathrm{SbSb}$ or AsAs stretching and heavy atom bending) and intermolecular motions, we have performed a normal coordinate analysis (NCA) of I, II and III which is based on an investigation of $\mathrm{R}_{3} \mathrm{Sb}$ and $\mathrm{R}_{3} \mathrm{As}$ molecules, $\mathrm{R}=\left(\mathrm{CH}_{3}\right)_{3} \mathrm{Si}$ [10] . Furthermore the NCA will help to clarify the open question of SbSb stretching vibrations and rotamers in I which has not been answered unambiguously [9] .

\section{EXPERIMENTAL}

Materials

The compounds I [11], II [7], III [4] and IV [12] were prepared as described in the literature.

Spectra

Raman spectra were recorded with a Cary 82 spectrometer, excitation $\mathrm{Kr}^{+}$ $647.1 \mathrm{~nm}, 50-300 \mathrm{~mW}$ at the sample, employing sealed $1 \mathrm{~mm}$ i.d. capillaries 
and devices which allowed cooling $\left(-50^{\circ} \mathrm{C}\right)$ and heating of the samples up to $120^{\circ} \mathrm{C}$. Spectral slit widths were 0.6 to $4 \mathrm{~cm}^{-1}$, wavenumber accuracy $\pm 1-2 \mathrm{~cm}^{-1}$. Infrared spectra were recorded on Nujol mulls in the 4000$300 \mathrm{~cm}^{-1}$ region with a Perkin-Elmer 583B spectrometer, resolution $1-3 \mathrm{~cm}^{-1}$, wavenumber accuracy $\pm 2 \mathrm{~cm}^{-1}$, while the 500 to $>100 \mathrm{~cm}^{-1}$ region was studied with a Nicolet Series 8000 vacuum FT spectrometer employing polythene discs (II-IV) or a $0.2 \mathrm{~mm}$ cell (I). The resolution was $1 \mathrm{~cm}^{-1}$ and the wavenumber accuracy $<1 \mathrm{~cm}^{-1}$.

\section{RESULTS}

\section{Internal vibrations}

The inner vibrations of the $\mathrm{CH}_{3}$ and $\mathrm{Si}\left(\mathrm{CH}_{3}\right)_{3}$ groups located $>600 \mathrm{~cm}^{-1}$ are barely sensitive to configurational changes and crystal packing and are therefore omitted from the following discussion. For I, they have been measured and assigned [9], and analogy to $\mathrm{Sb}\left(\mathrm{CH}_{3}\right)_{3}[13]$ and to $\left(\mathrm{CH}_{3}\right)_{3} \mathrm{Si} \mathrm{com}$ pounds [14] can be stated. Compound IV, which is not thermochromic, is not further treated except for the low-frequency region because our spectra essentially agree with those reported previously [9], though they reveal many additional details.

The notation of the inner vibrations of II and III, which are expected to occur $<500 \mathrm{~cm}^{-1}$, are given in Table 1 . Centrosymmetric $C_{2 \mathrm{~h}}$ symmetry as confirmed for the trans-configurated II was assumed. For the gauche conformation, $C_{2}$ symmetry, the $a_{\mathrm{g}}$ and $a_{\mathrm{u}}$ vibrations transform to $a$ and the $b_{\mathrm{g}}$ and $b_{\mathrm{u}}$ to $b$. For $\mathbf{I}$, only the vibrations $\nu(\mathrm{SbSb})$ and the skeleton deformations will appear below $400 \mathrm{~cm}^{-1}$, whereas substantial mixing of skeletal modes with the $\mathrm{SiC}_{3}$ deformations is expected for II and III.

The outstanding feature of the two Raman spectra of the thermochromic compounds I and II is a huge intensity increase for bands associated with the

\section{TABLE 1}

Nontorsional intramolecular skeletal vibrations $\left(<500 \mathrm{~cm}^{-1}\right)$ of $\mathrm{R}_{2} \mathrm{M} \rightarrow \mathrm{MR}$, molecules; $\mathrm{R}=\mathrm{Si}\left(\mathrm{CH}_{3}\right)_{3}, \mathrm{M}=\mathrm{As}, \mathrm{Sb}$

\begin{tabular}{|c|c|c|c|c|c|}
\hline & \multirow{2}{*}{$\begin{array}{l}C_{2} \\
C_{2 h}\end{array}$} & \multicolumn{2}{|l|}{$a$} & \multicolumn{2}{|l|}{$b$} \\
\hline & & $a_{\mathrm{g}}$ & $a_{\mathrm{u}}$ & $b_{\mathrm{g}}$ & $b_{\mathrm{u}}$ \\
\hline$\nu(\mathrm{MM})$ & & $v_{1}$ & & & \\
\hline$\nu\left(\mathrm{Si}_{2} \mathbf{M}\right)$ & & $\nu_{2}$ & $\nu_{10}$ & $v_{1}$ & $\nu_{25}$ \\
\hline$\delta\left(\mathbf{S i}_{2} \mathbf{M}\right)$ & & $\nu_{3}$ & & $v_{1}$ & \\
\hline$\gamma\left(\mathrm{Si}_{2} \mathrm{M}\right)$ & & $v_{4}$ & & $\nu_{19}$ & \\
\hline$\rho\left(\mathbf{S i}_{\mathbf{2}} \mathbf{M}\right)$ & & & $\nu_{11}$ & & $v_{26}$ \\
\hline$\delta_{S}\left(\mathrm{SiC}_{3}\right)$ & & $\nu_{5}$ & $v_{12}$ & $\nu_{20}$ & $v_{27}$ \\
\hline${ }^{\delta}$ as $\left(\mathrm{SiC}_{3}\right)$ & & $\nu_{6}, \nu_{7}$ & $\nu_{13}, v_{14}$ & $v_{21}, v_{2}$ & $v_{2 s}, v_{29}$ \\
\hline$\rho\left(\mathrm{SiC}_{3}\right)$ & & $\nu_{8}, \nu_{9}$ & $v_{15}, v_{16}$ & $\nu_{23}, v_{24}$ & $\nu_{30}, \nu_{31}$ \\
\hline
\end{tabular}


$\mathrm{SbSb}$ chain in the solid state, whereas the Raman lines of III have comparable intensity in both phases.

\section{Tetramethyldistibane (I)}

The solid and liquid phase Raman spectra in the $\Delta \nu=0$ to $550 \mathrm{~cm}^{-1}$ region are shown in Fig. 1. 'I'he former which was measured from $\Delta \nu=5 \mathrm{~cm}^{-1} \mathrm{up}$ wards comprises three intense lines at 52,142 and $181 \mathrm{~cm}^{-1}$. For the liquid, the line at $52 \mathrm{~cm}^{-1}$ is clearly absent and, instead of the sharp line at $181 \mathrm{~cm}^{-1}$, two components at 179 and ca. $188 \mathrm{~cm}^{-1}$ are observed. Since the presence of different rotamers was concluded from the temperature dependence of the Raman spectrum [9], we have reexamined the 146,179 and $188 \mathrm{~cm}^{-1}$ lines at various sample temperatures between 25 and $120^{\circ} \mathrm{C}$. However only small changes were found in relative peak heights between the "doublet" and the line at $146 \mathrm{~cm}^{-1}$, and the effect is not monotone (e.g. almost identical spectra are obtained at 25 and at $120^{\circ} \mathrm{C}$, see also Fig. 4 in ref. 9). We feel that these changes neither establish nor refute the presence of several rotamers of different energy in the liquid phase in a temperature-dependent ratio.

Both the results of the NCA and the occurrence of the $142 \mathrm{~cm}^{-1}$ line in the crystal exclude the possibility that this line is associated with $v(\mathrm{SbSb})$ of an individual rotamer; it is assigned to $\nu_{4}\left(\gamma \mathrm{SbC}_{2}\right)$. Because this wagging mode involves motion of the $\mathrm{Sb}$ atoms along the $\mathrm{Sb}-\mathrm{Sb}$ axis, coupling with $\nu_{1}$ is likely to occur, which also explains the high intensity of the $142 \mathrm{~cm}^{-1}$ band in the solid phase.

The proximity of the two lines at 179 and $188 \mathrm{~cm}^{-1}$ and their coalescence in the solid state in fact seem to favour the presence of two rotamers in the liquid phase, but several arguments against this conclusion persist:
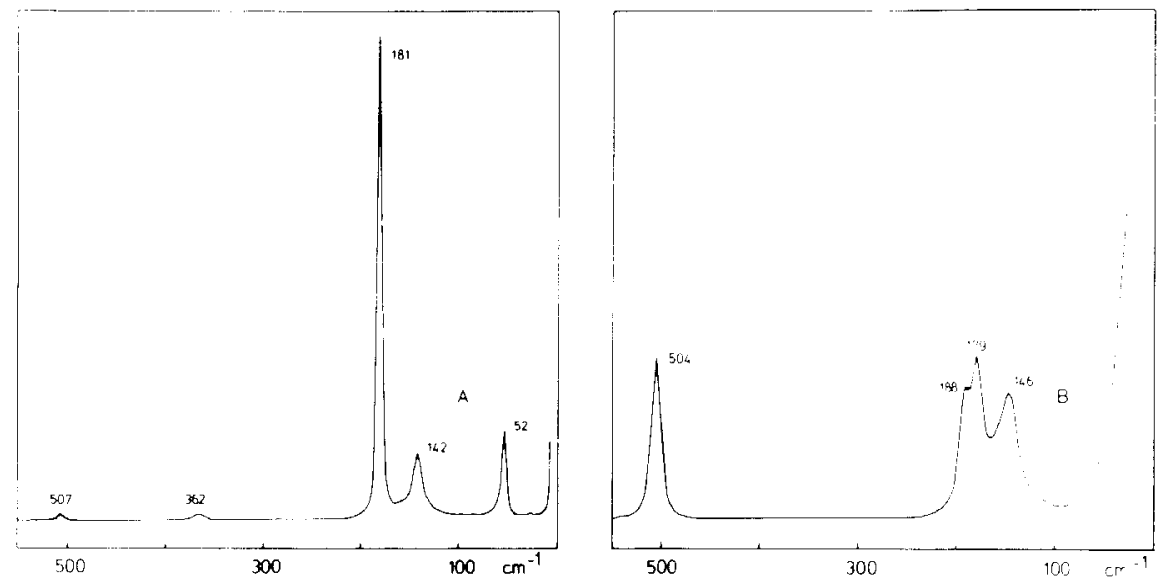

Fig. 1. Raman spectra of $\left(\mathrm{CH}_{3}\right)_{2} \mathrm{Sb}-\mathrm{Sb}\left(\mathrm{CH}_{3}\right)_{2}$ solid (A) and liquid phase (B). 
(i) The relative intensities of these two Raman lines should be sensitive to temperature changes, which is not the case.

(ii) The counterpart of the intense Raman line of $\left(\mathrm{CH}_{3}\right)_{3} \mathrm{Sb}$ at $188 \mathrm{~cm}^{-1}$ [13], associated with the $\delta_{\mathrm{s}}\left(\mathrm{SbC}_{3}\right)$ bending mode, would be missing if two rotamers are assumed to be present. The absence of the $\delta\left(\mathrm{SbC}_{2}\right)$ line $\left(\nu_{3}\right)$ in the solid state could be due to perfect accidental degeneracy, but blending by the contour of the extremely strong line associated with the $\mathrm{SbSb}$ stretching vibration may occur. If the relative intensity of $\nu_{3}$ is reduced to the same extent as that of $\nu\left(\mathrm{SbC}_{2}\right)$ at $504 \mathrm{~cm}^{-1}$, such blending seems even more likely.

(iii) No further splitting except that of $\nu$ (SbSb) is observed for the liquid phase. It is therefore concluded that the presence of more than one rotamer in the liquid state cannot be deduced with any certainty from the vibrational spectra of $I$.

The intense line observed in the solid state at $52 \mathrm{~cm}^{-1}$ cannot be associated with an intramolecular vibration because intensity and frequency considerations exclude its association with the torsion. This line is therefore assigned to an external mode, explicitly a longitudinal mode of an infinite diatomic chain. The FIR spectrum was re-examined since it proved impossible to assign the IR band reported at $230 \mathrm{~cm}^{-1}$ [9]. In contrast, it was found that the spectrum below $600 \mathrm{~cm}^{-1}$ consists of a strong absorption at $503 \mathrm{~cm}^{-1}$, two bands of medium intensity at 182 and $152 \mathrm{~cm}^{-1}$ and a weak feature around $110 \mathrm{~cm}^{-1}$. Except for the last, these absorptions correlate well with the $a_{\mathrm{g}}$ Raman lines and are assigned to the coinciding $a_{u} / b_{\mathrm{u}}$ vibrations $\nu\left(\mathrm{SbC}_{2}\right)$ and the $b_{\mathrm{u}}$ scissors and wagging deformations. The $110 \mathrm{~cm}^{-1}$ band is attributed to the $a_{\mathrm{u}}$ twist mode.

Tetrakis(trimethylsilyl)-diarsane (III) and -distibane (II)

The IR and Raman spectra of III and II are collected in Table 2, while Fig. 2 reproduces the low-frequency part of both spectra. Though, for the diarsane III, the relative intensities of the Raman lines near $170 \mathrm{~cm}^{-1}$ are also slightly phase-dependent, III hardly compares with the appearance of II. The Raman spectrum of solid II is characterized by (i) a drastic intensity increase of the line at $138 \mathrm{~cm}^{-1}$, which is apparently associated with the $\mathrm{SbSb}$ stretch, and (ii) the appearance of a line at $47 \mathrm{~cm}^{-1}$ which is second in intensity.

Though, in the mclt, the Rayleigh line blends the $<60 \mathrm{~cm}^{-1}$ region (Fig. 2), the analogy to I and the NCA results strongly favour an intermolecular character of this vibration. Unassigned low-lying Raman lines and IR absorptions of the solid material may be due to overtones or combination bands involving intermolecular and torsional motions.

The assignment of the intramolecular vibrations given in Table 2 is based on the comparison with $\mathrm{As}\left[\mathrm{Si}\left(\mathrm{CH}_{3}\right)_{3}\right]_{3}$ and $\mathrm{Sb}\left[\mathrm{Si}\left(\mathrm{CH}_{3}\right)_{3}\right]_{3}[10]$ and the NCA. It should be noted that the M-M stretching vibration carries "hybrid" character due to mixing with bending modes, different potential energy distributions resulting for $\mathrm{M}=\mathrm{As}$ and $\mathrm{M}=\mathrm{Sb}$. Thus, the intensity changes of 


\section{TABLE 2}

Infrared and Raman spectra $\left(\mathrm{cm}^{-1}\right)$ of II and III

\begin{tabular}{|c|c|c|c|c|c|c|c|}
\hline \multicolumn{4}{|c|}{$\left[\left(\mathrm{CH}_{3}\right)_{3} \mathrm{Si}\right]_{2} \mathrm{Sb}-\mathrm{Sb}\left[\mathrm{Si}\left(\mathrm{CH}_{3}\right)_{3}\right]_{2}(\mathrm{II})$} & \multicolumn{4}{|c|}{$\left[\left(\mathrm{CH}_{3}\right)_{3} \mathrm{Si}\right]_{2} \mathrm{As}-\mathrm{As}\left[\mathrm{Si}\left(\mathrm{CH}_{3}\right)_{3}\right]_{2}(\mathrm{III})$} \\
\hline $\mathrm{IR}_{\text {mull }}$ & $\mathrm{R}_{\text {liq. }}$ & $\mathrm{R}_{\text {cryst. }}$ & Assignment & $\mathrm{IR}_{\text {mul1 }}$ & $\mathrm{R}_{\text {liq. }}$ & $R_{\text {cryst. }}$ & Assignment \\
\hline \multirow{6}{*}{$\begin{array}{r}89 \mathrm{vw} \\
108 \mathrm{vw}\end{array}$} & & $46 \mathrm{~s}$ & a & & & & \\
\hline & $73 \mathrm{w}$ & $65 \mathrm{sh}$ & $\nu_{4}, v_{19}$ & & $73 \mathrm{~ms}$ & & $v_{4}, v_{19}$ \\
\hline & & $88 \mathrm{vw}$ & $\nu_{3}$ & & $93 \mathrm{~m}(\mathrm{p})$ & $98 \mathrm{~s}$ & \\
\hline & & $107 \mathrm{vw}$ & 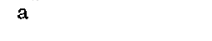 & & $155 \mathrm{w}$ & $155 \mathrm{sh}$ & $v_{23}, v_{24}$ \\
\hline & $140 v s(p)$ & 137 vs & $\nu_{1}$ & & $161 \mathrm{vs}(\mathrm{p})$ & $161 \mathrm{~m}$ & \\
\hline & $162 \mathrm{sh}$ & & $\nu_{8}$ & & $175 \mathrm{sh}$ & $179 \mathrm{~s}$ & $v_{8}$ \\
\hline \multirow{4}{*}{$\begin{array}{l}189 \mathrm{w} \\
230 \mathrm{vw}\end{array}$} & $188 \mathrm{~s}(\mathrm{p})$ & $191 \mathrm{~m}$ & $\delta_{\mathrm{S}}\left(\mathrm{SiC}_{3}\right)$ & & $206 \mathrm{~m}$ & $205 \mathrm{~m}$ & $\nu_{5}, \nu_{20}$ \\
\hline & $\sim 235 \mathrm{vw}(\mathrm{b})$ & $237 \mathrm{w}$ & $\delta_{\text {as }}\left(\mathrm{SiC}_{3}\right)$ & & $235 \mathrm{w}$ & $233 \mathrm{w}$ & $\delta(\mathrm{SiC})$ \\
\hline & & & & $257 \mathrm{~m}$ & $247 \operatorname{sh}(p)$ & $250 \mathrm{w}$ & ${ }^{0}$ as $\left(\mathrm{Sic}_{3}\right)$ \\
\hline & & & & & $262 \mathrm{w}(\mathrm{p})$ & $264 \mathrm{vw}$ & $y_{1}$ \\
\hline \multirow[t]{2}{*}{$310 \mathrm{~s}$} & & $\begin{array}{l}273 \mathrm{w} \\
311 \mathrm{w}\end{array}$ & $\begin{array}{l}2 \times 137 \\
\nu_{10}, \nu_{17}\end{array}$ & $\begin{array}{l}286 \mathrm{w} \\
340 \mathrm{~s}\end{array}$ & & & $\nu_{10}$ \\
\hline & $322 s(p)$ & $322 \mathrm{sh}$ & $v_{2}$ & $\begin{array}{l}354 \mathrm{~s} \\
621 \mathrm{~s}\end{array}$ & $348 \mathrm{~s}(\mathrm{p})$ & $\begin{array}{l}349 \mathrm{~s} \\
620 \mathrm{sh}\end{array}$ & $v_{2}, v_{25}$ \\
\hline $614 \mathrm{~s}$ & $625 \mathrm{~m}(\mathrm{p})$ & $630 \mathrm{vw}$ & $v_{\mathrm{S}}\left(\mathrm{SiC}_{3}\right)$ & & $630 \mathrm{~s}(\mathrm{p})$ & $631 \mathrm{~s}$ & \\
\hline \multirow{4}{*}{$\begin{array}{l}684 \mathrm{~s} \\
736 \mathrm{~s} \\
750 \mathrm{sh} \\
835 \mathrm{vs}\end{array}$} & $688 w$ & $687 \mathrm{vw}$ & $v_{\mathrm{as}}\left(\mathrm{SiC}_{3}\right)$ & $689 \mathrm{~s}$ & $692 \mathrm{~m}$ & $690 \mathrm{~m}$ & \\
\hline & $\sim 740 \mathrm{w}$ & $747 \mathrm{~m}$ ) & & $741 \mathrm{~s}$ & & $740 \mathrm{sh}$ & \\
\hline & $755 \mathrm{w}(\mathrm{b})$ & & & $750 \mathrm{sh}$ & $751 \mathrm{w}$ & $752 \mathrm{w}$ & \\
\hline & $\sim 860 w(p)$ & $838 \mathrm{w})$ & $\rho\left(\mathrm{CH}_{3}\right)$ & $845 \mathrm{~s}$ & $\begin{array}{l}842 \mathrm{vw} \\
868 \mathrm{w}(\mathrm{p})\end{array}$ & $\begin{array}{l}838 w \\
865 w\end{array}$ & see II \\
\hline \multirow[t]{2}{*}{$1241 \mathrm{~s}$} & $1243 \mathrm{w}$ & $1242 \mathrm{vw}$ & & $1245 \mathrm{~s}$ & $1247 \mathrm{~m}$ & & \\
\hline & $1255 \mathrm{w}$ & $1255 \mathrm{w}$ & $\delta_{\mathbf{s}}\left(\mathrm{CH}_{3}\right)$ & $1258 \mathrm{~s}$ & $1263 \mathrm{~m}(\mathrm{p})$ & & \\
\hline \multirow{2}{*}{$\begin{array}{c}1305 \mathrm{w} \\
-\end{array}$} & & & $\nu_{\mathrm{s}}+\nu_{\text {as }}\left(\mathrm{SiC}_{3}\right)$ & $1308 \mathrm{w}$ & & & \\
\hline & $\begin{array}{l}1380 \mathrm{vw} \\
1410 \mathrm{vw}\end{array}$ & & $\delta_{\text {as }}\left(\mathrm{CH}_{3}\right)$ & - & $\begin{array}{l}1410 \mathrm{w} \\
1450 \mathrm{vw}(\mathrm{b})\end{array}$ & $\begin{array}{l}1409 \mathrm{~m} \\
1440 \mathrm{w}\end{array}$ & \\
\hline
\end{tabular}

asee text.

the lines at 160 and $180 \mathrm{~cm}^{-1}$ in III indicate different contributions, and since intermolecular interactions are weak, they could well result from a change of the conformation on phase transition.

Tetraphenyldistibane (IV)

The low-frequency IR and Raman spectra of IV are presented in Fig. 3. Though several low-frequency Raman lines are observed, none of these is of comparable intensity to the intramolecular $\mathrm{SbSb}$ stretching vibration at $141 \mathrm{~cm}^{-1}$. Since our results are generally in agreement with previous findings [9], they require no further comment.

NORMAL COORDINATE ANALYSIS

A NCA for I, II and III was performed employing a modified version of the NORCOR program [15]. Methyl groups were treated as points with a 

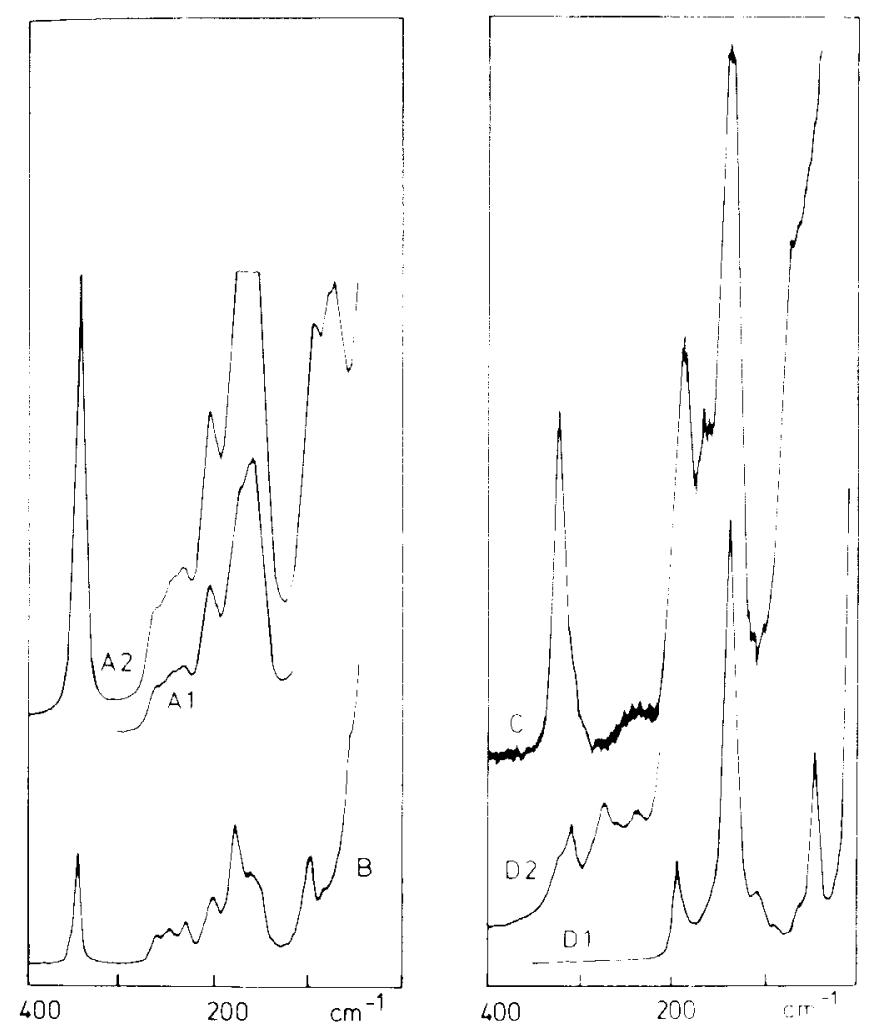

Fig. 2. Low -frequency Raman spectra of $\left[\left(\mathrm{CH}_{3}\right)_{3} \mathrm{Si}\right]_{2} \mathrm{As}-\mathrm{As}\left[\mathrm{Si}\left(\mathrm{CH}_{3}\right)_{3}\right]_{2}$ (A: liquid, B: solid) and $\left[\left(\mathrm{CH}_{3}\right)_{3} \mathrm{Si}\right]_{2} \mathrm{Sb}-\mathrm{Sb}\left[\mathrm{Si}\left(\mathrm{CH}_{3}\right)_{3}\right]_{2}(\mathrm{C}$ : liquid, D: solid).

mass of 15 , justification for this simplication being deduced from comparative calculations on the model $\left(\mathrm{CH}_{3}\right)_{3} \mathrm{SiI}$ with the (M-15) ${ }_{3} \mathrm{SiI}$ approximation and full treatment, transferring inner force constants of the $\left(\mathrm{CH}_{3}\right)_{3} \mathrm{Si}$ fragment from $\mathrm{Si}\left(\mathrm{CH}_{3}\right)_{4}[16]$. The mass point approximation yields force constants which are too low by 0.053 (SiI), 0.075 (SiC), 0.060 (CSiI) and $0.075 \mathrm{~N} \mathrm{~cm}^{-1}$ (CSiC).

Geometric parameters were taken as quoted $[7,8]$, a trans configuration with $r(\mathrm{SbSb}) 287 \mathrm{pm}, r(\mathrm{SbC}) 217 \mathrm{pm}, x(\mathrm{CSbC})$ and $(\mathrm{CSbSb}) 94^{\circ}$ being assumed for I though both trans and $c$ is conformations were considered for I and III. The final force constants for trans-configurated I are outlined in Table 3 . The PED of the eigenvalues 188 and $179 \mathrm{~cm}^{-1}$ is both sensitive to interaction constants and the assumed conformation. Table 4 demonstrates the insensitivity of frequencies in contrast to the PED changes upon conformation change for one single set of force constants. This concerns in particular the involvement of ( $\mathrm{SbSb}$ ) stretching character which in both cases contributes considerably to the $a_{(\mathrm{g})}$ fundamental near $145 \mathrm{~cm}^{-1}$.

The NCA confirms the qualitative conclusion that: (i) the two $a_{\mathrm{g}}$ modes at 188 and $179 \mathrm{~cm}^{-1}$ do not interfere significantly; (ii) slight changes of the 


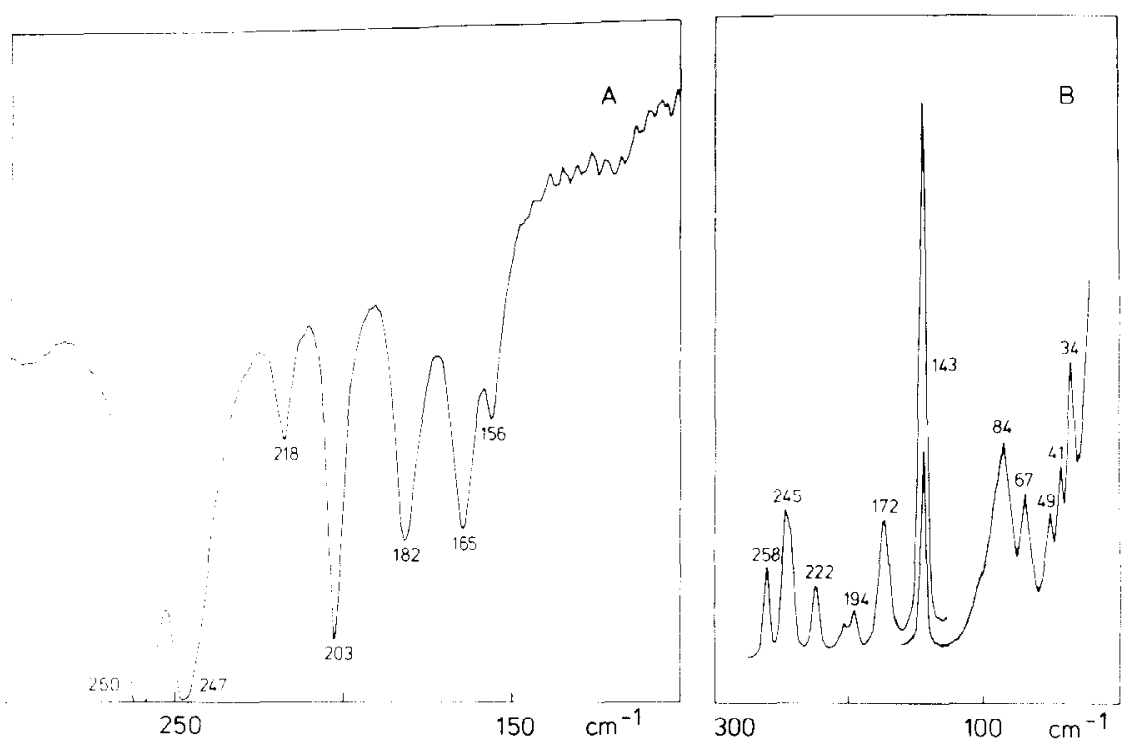

Fig. 3. Far-infrared (A) and low-frequency Raman spectrum (B) of $\left(\mathrm{C}_{6} \mathrm{H}_{3}\right)_{2} \mathrm{Sb}-\mathrm{Sb}\left(\mathrm{C}_{6} \mathrm{H}_{3}\right)_{2}$.

\section{TABLE 3}

Non-zero inner force constants $\left(\mathrm{N} \mathrm{cm}{ }^{1}\right.$ ) of $R_{2} M-M R_{2}$ compounds

\begin{tabular}{|c|c|c|c|c|}
\hline$f^{a}$ & $\begin{array}{l}M= \\
R=\end{array}$ & $\begin{array}{l}\mathrm{Sb} \\
\mathrm{CH}_{3}\end{array}$ & $\begin{array}{l}\mathrm{Sb} \\
\mathrm{Si}\left(\mathrm{CH}_{3}\right)_{3}\end{array}$ & $\begin{array}{l}\text { As } \\
\mathrm{Si}\left(\mathrm{CH}_{3}\right)_{3}\end{array}$ \\
\hline $\mathrm{R}$ & & 1.11 & 1.12 & 1.5 \\
\hline$r$ & & 1.99 & 1.67 & 1.73 \\
\hline$s$ & & & 2.69 & 2.72 \\
\hline$\alpha$ & & 0.62 & 0.95 & 1.10 \\
\hline$\beta$ & & 0.73 & 0.87 & 0.82 \\
\hline$\omega$ & & & 0.46 & 0.46 \\
\hline$\xi$ & & & 0.56 & 0.58 \\
\hline $\mathrm{Rr}$ & & 0.0 & 0.10 & 0.10 \\
\hline$r r$ & & 0.02 & 0.07 & 0.05 \\
\hline rs & & & 0.04 & 0.04 \\
\hline ss & & & 0.11 & 0.11 \\
\hline$\beta \beta^{\prime \prime \prime}(c i s)$ & & 0.09 & 0.07 & 0.07 \\
\hline$\omega \omega$ & & & 0.01 & 0.01 \\
\hline$\zeta \zeta$ & & & 0.015 & 0.03 \\
\hline$R_{\beta}$ & & 0.11 & 0.16 & 0.20 \\
\hline $\mathbf{R}_{\zeta}$ & & & 0.02 & 0.05 \\
\hline$r \omega$ & & & -0.12 & -0.13 \\
\hline$r \zeta$ & & & 0.12 & 0.13 \\
\hline \multicolumn{5}{|c|}{$\begin{array}{l}\omega \zeta-0.01, \omega \zeta^{\prime} 0.05, \mathrm{~s} \omega=-s \omega^{\prime}=-s \zeta=s \xi^{\prime}-0.12, \\
\beta \beta^{\prime}(\text { gem. })=-\beta \beta^{\prime \prime}(\text { trans }) 0.07\end{array}$} \\
\hline
\end{tabular}

${ }^{\mathrm{a}} \mathrm{R}=\mathrm{MM}, r=\mathrm{SbC} / \mathrm{MSi}, \mathrm{s}=\mathrm{SiC}, \alpha=\mathrm{CSbC} / \mathrm{SiMSi}, \beta=\mathrm{CSbSb} / \mathrm{SiMM}, \omega=\mathrm{CSiC}, \zeta=\mathrm{CSiM}$. 
TABLE 4

Observed and calculated vibrational frequencies $\left(\mathrm{cm}^{-1}\right)$ for $\left(\mathrm{CH}_{3}\right)_{2} \mathrm{Sb}-\mathrm{Sb}\left(\mathrm{CH}_{3}\right)_{2}$ in trans and gauche conformation and respective $\mathrm{PED}^{\mathrm{a}}$

\begin{tabular}{lcccccc}
\hline & \multicolumn{2}{l}{ trans } & & & \multicolumn{2}{l}{ gauche } \\
\cline { 2 - 3 } & $\nu_{\text {obs. }}$ & $\nu_{\text {calc. }}$ & PED $\times 100$ & & $v_{\text {calc. }}$ & PED $\times 100$ \\
\hline$a_{(\mathrm{g})}$ & 504 & 504 & $99(\mathrm{r})$ & 504 & $99(\mathrm{r})$ \\
& 188 & 188 & $56(\alpha), 31(\beta), 17(\mathrm{R})$ & 182 & $97(\alpha)$ \\
& 179 & 179 & $59(\mathrm{R}), 37(\alpha), 21(\beta)$ & 180 & $80(\mathrm{R}), 41(\beta)$ \\
& 146 & 146 & $41(\beta), 30(\mathrm{R})$ & 142 & $57(\beta), 23(\mathrm{R})$ \\
$a_{(\mathrm{u})}$ & 503 & 503 & $101(\mathrm{r})$ & 503 & $101(\mathrm{r})$ \\
& 110 & 110 & $145(\beta)$ & 118 & $139(\beta)$ \\
$b_{(\mathrm{g})}$ & 503 & 504 & $101(\mathrm{r})$ & 504 & $101(\mathrm{r})$ \\
& & 159 & $89(\beta)$ & 163 & $84(\beta), 13(\alpha)$ \\
$b_{(\mathrm{u})}$ & 503 & 503 & $99(\mathrm{r})$ & 503 & $99(\mathrm{r})$ \\
& 182 & 182 & $100(\alpha)$ & 185 & $86(\alpha), 11(\beta)$ \\
& 152 & 152 & $93(\beta)$ & 143 & $89(\beta)$ \\
\hline
\end{tabular}

aPotential energy distribution PED exceeding 0.1 in terms of inner force constants; for notation see Table 3 .

geometry or interactions may reduce the (SbSb) stretching character and intensity of the $188 \mathrm{~cm}^{-1}$ Raman line; and (iii) independent of the chosen geometry the vibration at $146 \mathrm{~cm}^{-1}$ retains considerable ( $\mathrm{SbSb}$ ) stretching character.

The trimethylsilyl compounds reveal a different coupling pattern. For II, both the $\nu(\mathrm{SbSb})$ and $\rho\left(\mathrm{SiC}_{3}\right)$ modes are expected to appear close to $160 \mathrm{~cm}^{-1}$, while the $\gamma\left(\mathrm{SbSi}_{2}\right)$ mode $\nu_{4}$ should be sufficiently low as to not interact with the former. Due to the mixing of $\nu_{1}$ with $\rho\left(\mathrm{SiC}_{3}\right)$ an in-phase $a_{\mathrm{g}}$ component at low frequency, $140 \mathrm{~cm}^{-1}$, carrying high Raman intensity and an out-ofphase component of low Raman intensity appear. The latter is not distinctly visible in the spectrum because of blending by $\delta_{\mathrm{s}}\left(\mathrm{SiC}_{3}\right)$ at ca. $190 \mathrm{~cm}^{-1}$ but presumably is responsible for the $5 \mathrm{~cm}^{-1}$ shift of this feature caused by the liquid to solid phase transition. The observed and calculated vibrational frequencies and the PED are set out in Table 5.

Due to the comparability of the As and $\mathrm{Si}\left(\mathrm{CH}_{3}\right)_{3}$ masses coupling is even more pronounced for III. Prominent Raman lines clearly attributable to $\nu$ (AsAs) are missing, broad features being observed instead. The strongest line at $160 \mathrm{~cm}^{-1}$ is too low to carry predominantly $\nu_{1}$ character, though this mode again involves an in-phase motion of the heavy atoms. The intensity change associated with the phase transition (Fig. 2) furthermore suggests a sensitivity to the surroundings or a conformational change which is less likely for a $\nu$ (AsAs) rather than a $\rho\left(\mathrm{SiC}_{3}\right)$ mode. The NCA predicts two further vibrations at ca. 225 and $265 \mathrm{~cm}^{-1}$ to carry $\nu$ (AsAs) character, 20 and $60 \%$ respectively. Therefore, the highest (polarized) component of the band cluster extending from 225 to $275 \mathrm{~cm}^{-1}$ may be assigned to $\nu$ (AsAs). 
TABLE 5

Observed and calculated vibrational frequencies $\left(\mathrm{cm}^{-1}\right)$ for trans-II, trans-III and respective PED $^{\mathrm{a}}$

\begin{tabular}{|c|c|c|c|c|c|c|}
\hline & {$[(\mathrm{CH}$} & $\left.\left({ }_{3}\right)_{3} \mathrm{Si}\right]_{2} \mathrm{~S}$ & $\mathrm{~b}-\mathrm{Sb}\left[\mathrm{Si}\left(\mathrm{CH}_{3}\right)_{3}\right](\mathrm{II})$ & {$[(\mathrm{CH}$} & ${ }_{3} \mathrm{Si}_{2} \mathrm{~F}$ & $s-\operatorname{As}\left[\mathrm{Si}\left(\mathrm{CH}_{3}\right)_{3}\right]_{2}$ (III) \\
\hline & "obs. & $\nu_{\text {calc }}$ & PED $\times 100$ & $v_{\text {obs. }}$ & $\nu_{\text {calc. }}$ & $\mathrm{PED} \times 100$ \\
\hline$a_{\mathrm{g}}$ & 322 & 322 & $94(\mathrm{r}), 21(\zeta), 17(\omega)$ & 348 & 350 & $90(r), 15(\zeta), 10(\omega)$ \\
\hline & 235 & 238 & $71(\omega), 21(\zeta), 13(\alpha)$ & 262 & 266 & $63(\mathrm{R}), 29(\zeta), 20(\beta), 9(\omega)$ \\
\hline & 235 & 1233 & $74(\omega), 15(\zeta), 9(\beta)$ & 247 & 251 & $50(\omega), 31(\zeta), 18(\alpha)$ \\
\hline & & 194 & $49(\omega), 44(\zeta), 8(\mathrm{R}), 7(\beta)$ & 235 & 225 & $77(\omega), 24(\mathrm{R})$ \\
\hline & 188 & 190 & $46(\zeta), 40(R), 26(\omega)$ & 206 & 208 & $72(\omega), 32(\zeta)$ \\
\hline & 162 & 162 & $74(\zeta), 24(\omega)$ & 175 & 166 & $69(\xi), 30(\omega)$ \\
\hline & 140 & 139 & $61(\mathrm{R}), 42(\zeta), 5(\omega)$ & 161 & 154 & $68(\zeta), 22(R), 15(\omega)$ \\
\hline & $(88)$ & 80 & $46(\beta), 30(\alpha), 18(\zeta)$ & 93 & 92 & $48(\beta), 26(\zeta), 21(\alpha)$ \\
\hline & (65) & 59 & $47(\alpha), 35(\beta), 11(\zeta)$ & 73 & 68 & $48(\alpha), 28(\beta), 17(\zeta)$ \\
\hline$a_{\mathrm{u}}$ & 310 & 310 & $107(r), 23(\zeta), 19(\omega)$ & 340 & 337 & $110(\mathrm{r}), 16(\zeta), 12(\omega)$ \\
\hline & 230 & 227 & $90(\omega), 7(\zeta)$ & & 230 & $85(\omega), 12(\zeta)$ \\
\hline & 230 & 225 & $93(\omega), 8(\zeta)$ & & 227 & $86(\omega), 14(\zeta)$ \\
\hline & 189 & 189 & $55(\zeta), 41(\omega), 5(\mathrm{r})$ & & 206 & $54(\omega), 51(\zeta)$ \\
\hline & & 160 & $95(\zeta), 15(\omega)$ & & 163 & $94(\zeta), 19(\omega)$ \\
\hline & & 158 & $94(\zeta), 13(\omega)$ & & 161 & $94(\zeta), 16(\omega)$ \\
\hline & & 38 & $124(\beta)$ & & 40 & $125(\beta), 5(\zeta)$ \\
\hline$b_{\mathrm{g}}$ & $(311)$ & 313 & $106(\mathrm{r}), 22(\zeta), 17(\omega)$ & & 348 & $101(\mathrm{r}), 13(\zeta), 7(\beta)$ \\
\hline & $(235)$ & 230 & $84(\omega), 10(\zeta), 6(\beta)$ & $(233)$ & 238 & $62(\omega), 29(\zeta), 13(\beta)$ \\
\hline & $(200)$ & 225 & $94(\omega), 8(\zeta)$ & & 226 & $88(\omega), 12(\zeta)$ \\
\hline & & 194 & $51(\zeta), 45(\omega)$ & & 213 & $70(\omega), 36(\zeta)$ \\
\hline & & 161 & $92(\zeta), 17(\omega)$ & & 164 & $89(\zeta), 21(\omega)$ \\
\hline & & 158 & $94(\zeta), 13(\omega)$ & 155 & 161 & $94(\zeta), 16(\omega)$ \\
\hline & 73 & 75 & $76(\beta), 11(\zeta)$ & 93 & 91 & $66(\beta), 17(\zeta), 6(r)$ \\
\hline$b_{\mathrm{u}}$ & & 321 & $96(x), 21(\zeta), 17(\omega)$ & 354 & 344 & $95(\mathrm{r}), 17(\zeta), 11(\omega)$ \\
\hline & 230 & 238 & $71(\zeta), 14(\omega), 12(\alpha)$ & 257 & 252 & $51(\omega), 28(\zeta), 14(\alpha)$ \\
\hline & 230 & 232 & $80(\zeta), 12(\omega), 6(\beta)$ & & 239 & $64(\omega), 24(\zeta), 8(\beta)$ \\
\hline & 189 & 190 & $51(\zeta), 49(\omega)$ & & 205 & $65(\omega), 40(\zeta)$ \\
\hline & & 174 & $81(\zeta), 26(\omega), 6(\beta)$ & & 184 & $67(\zeta), 43(\omega), 6(\beta)$ \\
\hline & & 162 & $73(\xi), 25(\omega)$ & & 166 & $68(\zeta), 30(\omega)$ \\
\hline & & 70 & $71(\alpha), 19(\zeta), 6(\beta)$ & & 81 & $56(\alpha), 29(\zeta), 9(\beta)$ \\
\hline & & 60 & $73(\beta), 13(\xi), 7(\alpha)$ & & 65 & $65(\beta), 17(\zeta), 12(\alpha)$ \\
\hline
\end{tabular}

a Potential energy distribution PED exceeding 0.05 in terms of inner force constants; see Table 3 for notation. 
Consequently any evaluation of the AsAs stretching force constant is ambiguous, frequencies being less sensitive to $f(\mathrm{AsAs})$ than to interaction force constants. The calculated frequencies and their PED (Table 5) are insensitive to conformational changes $\left(\left|\nu_{\text {trans }}-v_{\text {gauche }}\right|<5 \mathrm{~cm}^{-1}\right)$.

\section{Intermolecular interactions}

Because of the large energy separation between intra- and intermolecular modes, $\mathrm{Sb}_{2}\left(\mathrm{CH}_{3}\right)_{4}$ can be treated as an infinite chain of two mass points with $M_{\text {eff }}=151$ yielding $f\left(\mathrm{Sb}^{\cdots} \mathrm{Sb}\right)=0.121 \mathrm{~N} \mathrm{~cm}^{-1}$. A full NCA treatment involving a chain of 5 molecules $(k=4)$ yields almost the same value, $0.125 \mathrm{~N} \mathrm{~cm}^{-1}$. For compound II, however, kinctic coupling with the low-encrgy skeletal bending modes becomes important, a calculation of $f(\mathrm{SbSb})$ assuming a simple chain model not being possible. Since a full NCA treatment with the used program was precluded by the number of atoms in even two molecules, model calculations were performed which proved that coupling between inter- and intramolecular SbSb stretching coordinates was neglectable. Thus, an approximative intermolecular force constant for the hypothetical unit, $\left[(\mathrm{M}-15)_{3} \mathrm{Si}\right]_{2} \mathrm{Sb} \cdots \mathrm{Sb}\left[\mathrm{Si}(\mathrm{M}-15)_{3}\right]_{2}, f(\mathrm{Sb} \cdots \mathrm{Sb}) 0.18 \mathrm{~N} \mathrm{~cm}^{-1}$, could be deduced. The PED (without interaction force constants of the $\mathrm{Sb} \cdots \mathrm{Sb}$ coordinate) indicates contributions from the SbSbSi and SiSbSi bending coordinates as high as $30 \%$.

\section{DISCUSSION}

The solid state Raman spectra of I-IV correlate well with the results of structural investigations. Only the thermochromic distibanes I and II give rise to a strong line near $50 \mathrm{~cm}^{-1}$ and a considerable increase of the modes associated with the $\mathrm{Sb}-\mathrm{Sb}$ stretch. In an infinite chain of $\mathrm{R}_{2} \mathrm{Sb}-\mathrm{SbR}_{2}$ units, the former corresponds to the longitudinal acoustic and the latter to the optic mode. Because of the energy gap between intra-and intermolecular vibrations, the intermolecular force constant $f(\mathrm{Sb} \cdots \mathrm{Sb}), 0.125 \mathrm{~N} \mathrm{~cm}^{-1}$, is well determined for the methyl derivative I. Irrespective of the chosen model a larger value, $0.18 \mathrm{~N} \mathrm{~cm}^{-1}$, is derived for the trimethylsilyl compound II, the uncertainty being due to coupling with low-lying intramolecular bending modes. Apparently the thermochromic effect is associated with the linear arrangement of the molecule, while the colour seems not to be directly correlated with the intermolecular distance, e.g. the Sb $\cdots$ Sb distance of II exceeds that of the distibolyl [4] by $36.5 \mathrm{pm}$ and the force constants indicate an even larger distance for $\mathbf{I}$. Nevertheless the colour changes of $\mathbf{I}$, from purple blue at $-70^{\circ} \mathrm{C}$ via red at $0^{\circ} \mathrm{C}$ to yellow in the liquid-phase resembles that of the distibolyl.

The analysis of the intramolecular vibrations reveals that the interpretation of the spectra does not require several conformers to be present in the liquid or the solid phase. Thus, the spectra of I and II are fully consistent with trans 
configuration, and the intensity changes observed in III indicate that the liquid-phase configuration may well differ from the half-eclipsed conformation found in the crystal.

Intramolecular SbSb stretching force constants, ca. $1.1 \mathrm{~N} \mathrm{~cm}^{-1}$, were calculated for I and II, this value being better defined by the former case. On the other hand, extensive coupling and ambiguous assignments only allow an estimate of $f$ (AsAs).

\section{REFERENCES}

1 F. A. Paneth, Trans. Faraday Soc., 30 (1934) 179; F. A. Paneth and H. Loleit, J. Chem. Soc., (1935) 366.

2 H. J. Breunig and V. Breunig-Lyriti, Z. Naturforsch. Teil B, 34 (1979) 926.

3 H. J. Breunig, Z. Naturforsch. Teil B, 33 (1978) 244.

4 G. Becker, G. Gutekunst and H. J. Wessely, Z. Anorg. Allg. Chem., 462 (1980) 113.

5 A. J. Ashe, III, W. Butler and T. R. Diephouse, J. Am. Chem. Soc., 103 (1981) 207.

6 K. Von Deuten and D. Rehder, Cryst. Struct. Commun., 9 (1980) 167.

7 G. Becker, H. Freudenblum and C. Witthauer, Z. Anorg. Allg. Chem., 492 (1982) 370.

8 G. Becker, G. Gutekunst and C. Witthauer, Z. Anorg. Allg. Chem., 486 (1982) 90.

9 H. J. Breunig, V. Breunig-Lyriti and W. Fichtner, Z. Anorg. Allg. Chem., 487 (1982) 111.

10 H. Bürger and U. Goetze, Spectrochim. Acta, Part A, 26 (1970) 671.

11 H. J. Breunig, V. Breunig-Lyriti and T. P. Knobloch, Chem. Ztg., 101 (1977) 399.

12 W. Hewertson and H. R. Watson, J. Chem. Soc., (1962) 1490.

13 H. Siebert, Z. Anorg. Allg. Chern., 273 (1953) 161.

14 H. Bürger, Organomet. Chem. Rev., Ser. A, 3 (1968) 425.

15 D. Christen, J. Mol. Struct., 48 (1978) 101.

16 S. Biedermann, H. Bürger, K. Hassler and F. Höfler, Monatsh. Chem., 111 (1980) 715. 